\title{
Consecuencias de las políticas neoliberales en los mercados laborales de Estados Unidos y Alemania Enrique Casais Padilla*
}

Resumen

Desde la década de 1970, las principales economías capitalistas presentan una crisis de rentabilidad que motivó al capital internacional a buscar alternativas de rendimiento. Con el objetivo de maximizar las tasas de ganancia, entre otras medidas, se proponen reformas en los mercados laborales. Esta estrategia se inicia en Estados Unidos y es rápidamente secundada por gobiernos latinoamericanos y por el Reino Unido. En Alemania este proceso tarda en imponerse unos años, debido principalmente a aspectos políticos, como la presencia de sindicatos laborales fuertemente organizados y la existencia de la extinta Unión Soviética, que ejercía un contrapoder real a la hegemonía estadunidense. El artículo aborda las consecuencias socio-económicas de las reformas laborales en Estados Unidos y Alemania, que principalmente impusieron contenciones salariales y el deterioro de la calidad de vida de la mayoría de los trabajadores unido a importantes aumentos de la desigualdad.

Palabras clave: reformas laborales, desigualdad, Estados Unidos, Alemania.
Abstract

Since the 1970 s, the major capitalist economies have a profitability crisis that led to international capital to seek alternative performance. In order to maximize profit rates, among other measures, these reforms proposed labor market reforms. This strategy began in the United States, and is quickly seconded by many Latin American governments and the United Kingdom. In Germany this process took a few years mainly due to political issues such as the existence of a strongly organized labor unions, and the existence of the Soviet Union, who exercised counterweight to U.S. hegemony. This article addresses the socioeconomic consequences of these reforms of labor markets in the U.S. and Germany, which mainly imposed wage restraints and the deterioration of the quality of life of the majority of workers linked to significant increases in inequality.

Keywords: Labor market reforms, inequality, United States, Germany.

* Profesor de la Universidad Complutense de Madrid. Correo electrónico: enriquecasais@yahoo.es 


\section{Introducción}

A partir del nuevo orden surgido tras la Segunda Guerra Mundial, los mercados laborales se organizaron dentro del sistema de Estado-nación. Por consiguiente, independientes y aislados de cualquier competencia internacional que otros mercados laborales más favorables a los intereses del capital pudieran ofertar. Durante este periodo, los Estado-nación pudieron diseñar sus propias políticas y éstas estuvieron en mayor o menor medida influenciadas por los sindicatos y partidos políticos de izquierda. Este orden social relativamente favorable al desarrollo económico y a mejorar las condiciones de vida de los trabajadores se mantuvo hasta que se liberaron las restricciones internacionales impuestas a los flujos comerciales y de capital.

La larga historia de lucha de clases sobre los salarios, las condiciones de los contratos — duración de la jornada, la semana de trabajo y la vida laboral-, junto con las luchas por los niveles de las prestaciones sociales —el salario social—, son un testimonio de la importancia del límite potencial de la acumulación de capital. Por tanto, éste fue el principal bloqueo que había que superar si se quería avanzar en obtener mayores ganancias. La llamada "estrategia neoliberal" es, en definitiva, el modelo bajo el que los capitales internacionales se organizaron para tratar de revertir una situación que no favorecía sus intereses.

Así, se articularon tres factores que permitieron al capital internacional mejorar sus tasas de ganancia:

1. La flexibilización laboral.

2. La liberalización comercial y aduanera (globalización comercial).

3. La desregulación financiera (globalización financiera).

La flexibilización laboral busca deteriorar las condiciones de trabajo, el poder adquisitivo de los salarios y la protección social de los trabajadores. Pero estos intentos del capital de apropiarse de mayor parte del plusvalor no hubieran obtenido los resultados deseados sin la aplicación de los otros factores. La importancia de la liberalización comercial y desregulación financiera radica en el hecho de que éstas son capaces de acelerar la primera. El mecanismo por el que la globalización influye sobre los mercados laborales se manifiesta por la vía de la competencia internacional. 
A partir de estas reformas, todos los trabajadores del mundo deben competir por los trabajos disponibles a escala planetaria ya que permiten que cualquier bien se pueda producir en el lugar que sea más beneficioso para el capital. La globalización comercial y financiera es un elemento clave para imponer una mayor disciplina en las políticas fiscales y laborales de los Estado-nación ya que a partir de este momento, los capitales pueden moverse libremente y aprovechar los excedentes mundiales de trabajo a través de la deslocalización.

El objetivo del ensayo es mostrar cómo estas reformas de los mercados laborales han influido sobre los salarios y la calidad de vida de la gran mayoría de los trabajadores en dos de los países más industrializados del mundo, como son Estados Unidos y Alemania, el país central de la actual Unión Europea (UE), con trayectoria, cultura, evolución económica y laboral muy diferentes; y constatar cómo esta situación ha provocado en la economía una insuficiencia de demanda efectiva solvente.

El artículo se divide en dos grandes bloques: si bien el primer apartado se centra en las consecuencias que las reformas han tenido en Estados Unidos en lo referente a la contención salarial, y sus consecuencias sobre la desigualdad y el deterioro de la calidad de vida de la mayoría de los trabajadores, el segundo desarrolla algunos de los aspectos diferenciales del mercado laboral alemán, que permitan comprender por qué estas reformas tardan en imponerse en Europa Continental y constatar que aunque tardaron más tiempo en ver reflejados sus efectos sobre la gran mayoría de los trabajadores, finalmente, en esencia, han tenido similares consecuencias.

\section{Globalización y mercados laborales en Estados Unidos: contención salarial, desigualdad y crisis de demanda}

La globalización (financiera y comercial) y la deslocalización industrial consecuente de ella ha influido de manera importante en el tamaño y la composición de la fuerza laboral y los salarios de Estados Unidos. La fuerza de trabajo creció desde 62000000 en 1950 a 157000000 en 2010. En los últimos 40 años, las ocupaciones han mantenido una tendencia de disminución de la población dedicada a la agricultura y las manufacturas frente a los grandes incrementos de trabajo en el sector servicios. 
Los cambios en la composición de la población y las tasas de participación laboral han dado lugar a una fuerza de trabajo en la que cada vez tienen más peso los trabajadores estadunidenses de más edad, las mujeres, las minorías raciales y étnicas y las personas nacidas fuera de Estados Unidos. El crecimiento histórico de la fuerza laboral en las últimas cuatro décadas está vinculado a dos factores principales: el crecimiento de la población y el aumento de las tasas de participación laboral de las mujeres. En la década de 1960, la fuerza laboral aumentó 1.7\% anual y se aceleró durante la década de 1970 a medida que los baby boomers ${ }^{1}$ iban alcanzando la edad adulta. Al mismo tiempo, las mujeres comenzaron a incorporarse de manera significativa al mercado de trabajo (Lee y Mather, 2008:3).

La gráfica 1 muestra el comportamiento de los salarios, los precios y los incrementos de productividad en Estados Unidos entre 1947 y el año 2008. Los datos revelan que a partir de las reformas impuestas a mediados de la década de 1970, las ganancias del capital se van imponiendo en el reparto de la plusvalía generada. Durante el periodo, los salarios crecieron a una tasa media anual real de $0.9 \%$ que no fue lineal; entre 1947 y 1973, este crecimiento fue relativamente bueno para los trabajadores ya que los salarios reales crecieron en promedio $2.2 \%$ mientras la productividad aumentaba a un ritmo anual de $2.8 \%$. Pero en el ciclo económico de la década de 1980 esta situación se revertió a favor del capital; los trabajadores eran $1.4 \%$ más productivos cada año y su salario real disminuyó $0.6 \%$ en tasa promedio anual.

Del mismo modo, durante el ciclo económico 2000-2007, el crecimiento de la productividad fue $2.6 \%$ anual, mientras los salarios reales sólo crecieron $0.5 \%$ por año. Es realmente impresionante observar cómo el conjunto de los asalariados no ha tenido incrementos en sus salarios reales entre 1973-2008, mientras se ha dado un incremento anual de la productividad de $1.8 \%$ que, en términos acumulados, supone más de $100 \%$ durante el periodo.

La situación ha sido aún más grave para los trabajadores que perciben el salario mínimo; ${ }^{2}$ su salario real se redujo $0.9 \%$ por año en promedio

${ }^{1}$ Baby boomers son los nacidos entre 1946 y 1964, el periodo de mayor fertilidad de Estados Unidos.

${ }^{2}$ En 1938, el presidente Franklin Roosevelt firmó una ley histórica en el desarrollo social y económico de Estados Unidos: la Fair Labor Standards Act (FLSA). La legislación 


\section{Gráfica 1. Estados Unidos: evolución de salarios, precios y productividad, 1947-2008}

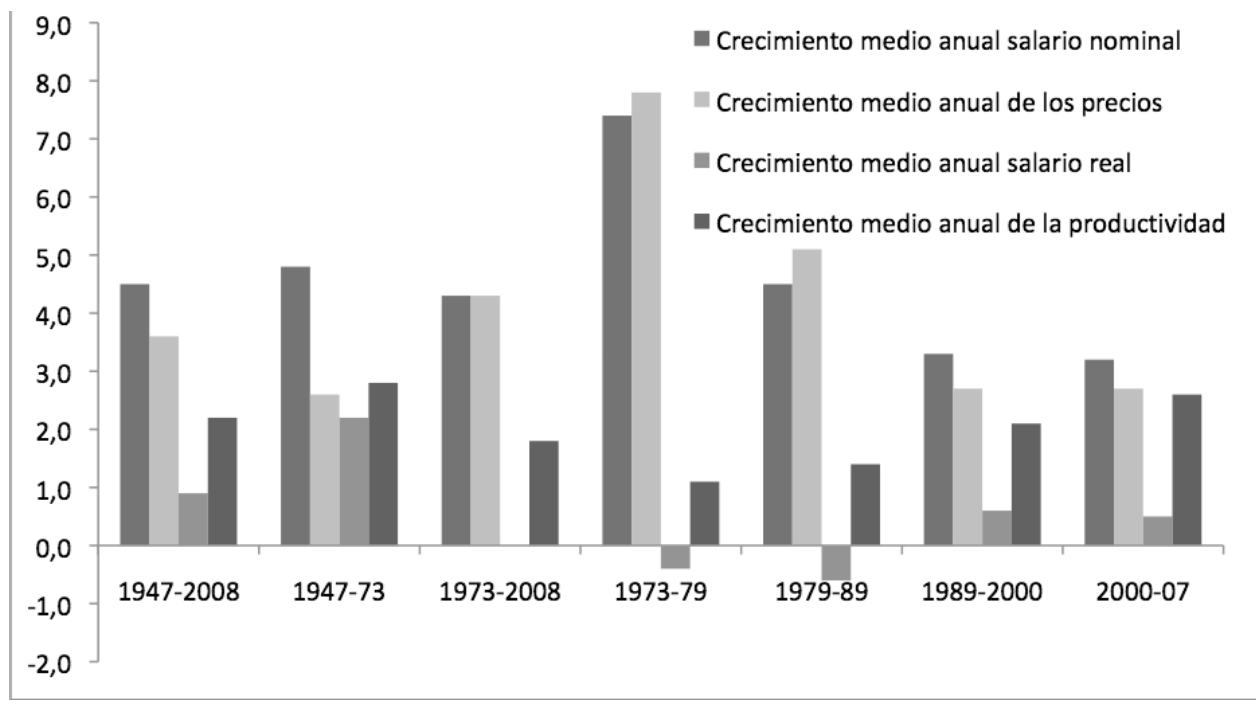

Fuente: Shierholz, 2011, citando datos del Bureau of Labor Statistics (BLS).

durante este periodo, a pesar de que la productividad promedio por hora de este grupo de trabajadores creció $112 \%$. Aún más: los trabajadores que ganan el salario mínimo han sufrido no sólo una erosión del valor real de sus salarios, sino que también han salido perjudicados con respecto de la media de salarios de la economía. En 1968, en su punto máximo, el salario mínimo representaba 53\% del salario medio, mientras en 2008 representaba algo menos de $40 \%$. Así, vemos que las políticas impuestas no sólo han servido para constreñir los salarios medios, sino también para ahondar la precariedad de los trabajadores menos cualificados de la sociedad. La competencia internacional impuesta por la globalización, como se ve, alcanza a todas las categorías de trabajadores (Shierholz, 2009).

fue diseñada para poner "un suelo a los salarios y un techo a las horas trabajadas" mediante el establecimiento de un salario mínimo nacional, establecer una semana laboral de 40 horas, y la prohibición de la mayoría del trabajo infantil. El salario mínimo estaba destinado a desempeñar un papel crucial en una estrategia para recompensar el trabajo, reducir la pobreza y asegurar que el crecimiento de la economía se distribuyera de manera más equitativa para el conjunto de los trabajadores. 


\section{La creciente desigualdad en Estados Unidos}

En 1970, el total de las remuneraciones, salarios y beneficios asistenciales de los empleados de Estados Unidos constituía las tres cuartas partes del ingreso personal. Los dividendos, intereses e ingresos rentistas contribuían 14\%, mientras que los beneficios asistenciales públicos, incluyendo discapacidad, desempleo y bienestar, eran menos de $8 \%$ del total (Mitchell, 2012).

Esta situación cambió en las décadas posteriores, conforme se impusieron los programas neoliberales que, como hemos visto, trataron de constreñir salarios y gasto público, principalmente gasto social. En 2010, los salarios, remuneraciones y beneficios asistenciales de los trabajadores eran ya sólo $64 \%$ del total, mientras aumentaron los porcentajes procedentes de dividendos, intereses y rentas. Esta menguante proporción de ingresos dimanantes de las remuneraciones provenientes del trabajo encaja con la más amplia erosión de la clase media estadunidense. Mientras en 1970 el consumo asociado a los trabajadores representaba $85 \%$ del total, en 2010 supuso sólo $61 \%$. El 39\% restante del gasto de los consumidores es generado por el quinto de hogares más ricos (Mitchell, 2012).

La economía de Estados Unidos, impulsada por los intereses del capital, está generando resultados económicos cada vez más desiguales donde $1 \%$ de la sociedad es cada vez más rico, frente a una gran mayoría que vive de su trabajo y que cada vez recibe una parte menor de la plusvalía generada. Esta tendencia dispar de salarios y rentas del capital ha provocado que desde 1979 hasta 2007 1\% de los hogares estadunidenses haya obtenido $59.9 \%$ de los ingresos, mientras que $0.1 \%$ se quedó con un escandaloso $36 \%$. Esto supone que en 2007, los ingresos medios anuales del $1 \%$ superior fueran 42 veces mayores que los ingresos del $10 \%$ inferior, frente a 14 veces mayor en 1979. Y los ingresos de la parte superior del $0.1 \%$ fueron 220 veces mayores, frente a 47 veces en 1979 (Bivens y Mishel, 2011).

La gráfica 2 muestra el crecimiento de los ingresos de manera global; es decir, incluyendo sueldos y salarios, intereses, dividendos y rentas de capital generadas. En el periodo anterior a la recesión actual, de 1979 a 2007, los ingresos ajustados a la inflación promedio anual del $1 \%$ de los hogares con mayores ingresos crecieron $224 \%$. Al $0.1 \%$ más rico le fue todavía mejor: un $390 \%$. En contraste, los ingresos del decil inferior crecieron apenas $5 \%$ en esos 28 años. 
Estos crecientes ingresos a favor de los más agraciados son en parte consecuencia de las importantes divergencias ocurridas en estos años en las remuneraciones salariales. Así, la relación entre la remuneración media obtenida por los directores ejecutivos (CEO) de las grandes empresas en relación con la compensación salarial de la media de los trabajadores era 24 veces mayor en 1965; en 1978 ya suponía 35 veces, 299 veces en el año 2000, el año que esta diferencia fue más acusada. ${ }^{3}$ Y para 2007, las remuneraciones alcanzaban 277 a 1.

\section{Gráfica 2. Incrementos de riqueza en Estados Unidos. Grupos de población seleccionados, 1979-2007}

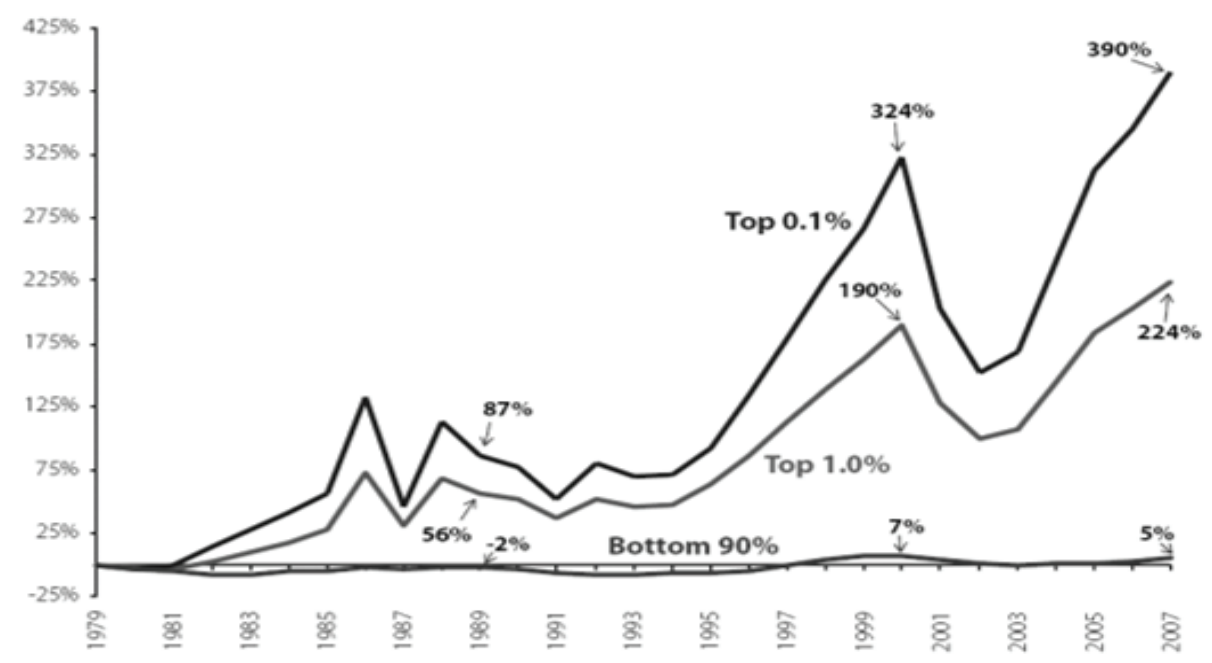

Fuente: Bivens y Mishel, 2011.

${ }^{3}$ Este nivel de compensación estaba sin duda inflado por el auge del mercado de valores a finales de 1990, y tuvo una contracción significativa después del estallido de la burbuja tecnológica. 
Las grandes beneficiadas de este periodo en Estados Unidos han sido las familias que ya poseían la mayoría de la riqueza a finales de la década de 1970, distanciándose de esta manera cada vez más de la clase media. La gráfica muestra cómo este proceso se acentúa de manera espectacular en la década de 1990. El periodo de principio de siglo se caracteriza por un breve lapso en el que parece que esta tendencia se frena, debido principalmente a las crisis de 2001. No obstante, una vez que se inicia la recuperación, el proceso vuelve a su patrón de desigual reparto de las riquezas generadas.

\section{Los problemas de demanda solvente en Estados Unidos}

Marx identificó el problema de la realización, que él consideraba intrínseco al capitalismo. Marx analiza la necesidad constante de expansión del capital estudiando el proceso de realización y la relación cuantitativamente desigual entre el trabajador como productor y el trabajador como consumidor de mercancías. ${ }^{4}$

Después de la Segunda Guerra Mundial, los salarios reales crecieron en proporción a la productividad del trabajo, lo que ayudó a financiar el crecimiento del consumo. Esta proporción se mantuvo más o menos constante hasta la década de $1980 .{ }^{5}$ A partir de esta década, esta situación no se da. Diversos cambios en las políticas gubernamentales de Estados Unidos provocaron, entre otros factores, que la participación de los salarios se fuera reduciendo como porcentaje del Producto Interno Bruto (PIB) real.

${ }^{4} \mathrm{El}$ salario del trabajador (correspondiente al trabajo necesario) debe ser menor que el valor total producido por el trabajador. Sin embargo, la plusvalía debe hallar un mercado adecuado a fin de realizarse. Como cada trabajador debe producir más valor que el que consume, la demanda del trabajador en tanto consumidor no podrá ser nunca una demanda suficiente para la plusvalía.

${ }^{5}$ La constancia de la participación salarial en el ingreso nacional, resultado de una estrecha relación entre la productividad del trabajo y el crecimiento de los salarios reales, era uno de los seis hechos típicos del crecimiento económico capitalista identificados por el economista de la Universidad de Cambridge (Reino Unido) Nicholas Kaldor en 1957. Una de las condiciones esenciales para la estabilidad es que el crecimiento del consumo se encuentre impulsado por el crecimiento de los salarios reales, y que éstos sean relativamente proporcionales a los crecimientos de la productividad. 
A medida que la participación salarial caía, el crecimiento del crédito al consumo se aceleraba y el consumo personal aumentaba como porcentaje del PIB.

La solución que permitió suprimir el crecimiento de los salarios reales mientras una proporción creciente del ingreso nacional se desviaba a los beneficios del capital fue resuelta por la "ingeniería financiera", que permitió una escalada significativa de la deuda del sector privado, principalmente entre los consumidores. El aumento de la deuda fue respaldado por la creación de una amplia gama de productos financieros de rápido crecimiento para ampliar su rentabilidad. Esta apropiación del ingreso real proporcionó los recursos que permitieron el crecimiento espectacular del sector financiero, pero a su vez significó que el crecimiento del consumo debía ser financiado a través de la aceleración del crédito. Todos los componentes de la deuda privada crecieron a partir de los años de la década de 1990, siendo los trabajadores/consumidores los principales deudores del sistema.

Dada la imposibilidad de la economía para seguir aumentando el consumo basado en una demanda efectiva real, la ingeniería financiera -unida a las bajas tasas de interés- permitió aumentar nuevamente el endeudamiento a principios del siglo xxi, hasta que la burbuja de crédito estalló. ${ }^{6}$ Como el crecimiento estaba mantenido por el aumento recurrente del crédito, una vez que éste se paró, la economía colapsó.

La gráfica 3 muestra el ahorro personal en Estados Unidos como porcentaje del ingreso personal disponible. La línea que cruza la gráfica en $7.1 \%$ representa el porcentaje promedio desde marzo de 1947 a septiembre de 2011. La disminución de la tasa de ahorro a partir de mediados de los años de 1980 se debe a que el crecimiento de los salarios reales se estaba constriñendo en Estados Unidos, y para mantener sus tasas de consumo, los hogares redujeron su tasa de ahorro.

Esta tendencia se aceleró en la segunda mitad de la década de 1990 cuando la desregulación de los mercados financieros permitió que éstos crearan todo tipo de instrumentos financieros, diseñados para impulsar

${ }^{6}$ Esta estrategia de crecimiento basado en un consumo apoyado en el endeudamiento creciente del sector privado fue insostenible. La estrategia se basaba en una ampliación continua de la base de la deuda por parte del sector financiero. Para ello, era necesario crear productos cada vez más arriesgados y obviar los límites razonables de endeudamiento de las familias. 


\section{Gráfica 3. Estados Unidos: ahorro personal como porcentaje del ingreso personal disponible}

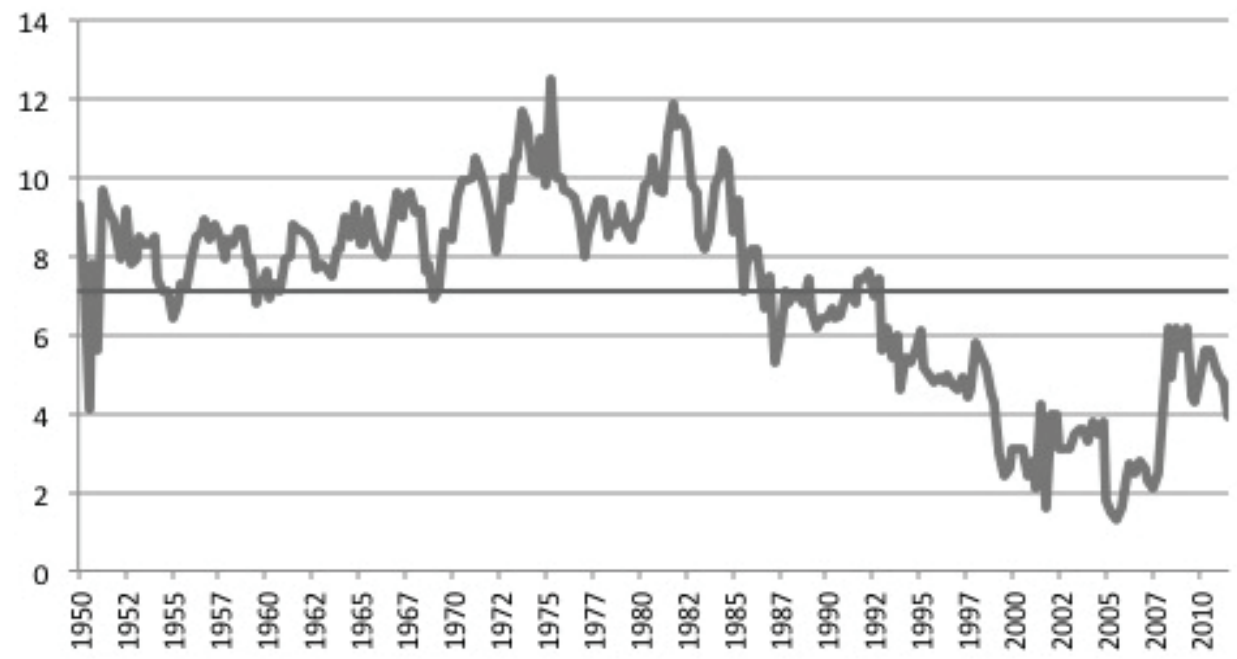

Fuente: Mitchell, 2012. Citando datos de US Bureau of Economic Analysis National Accounts Data.

cada vez más crédito al sector privado. La situación a lo largo de este periodo se ha vuelto insostenible, ya que la base sobre la que se asienta la demanda efectiva es principalmente deuda privada.

Así, las políticas de contención de salarios utilizadas como "solución" para garantizar unas ganancias al capital, terminan provocando nuevos episodios recurrentes de crisis debido a la insuficiente demanda efectiva solvente que mantenga el propio sistema capitalista.

De acuerdo con Marx, las crisis son, además de fenómenos inevitables dentro del capitalismo, eventos que ayudan al sistema a recuperarse de una insuficiente tasa de ganancia. Es decir, las crisis permiten descartar inversiones no rentables y, por medio del llamado "ejército industrial de reserva" —el número de trabajadores desempleados—, disminuir salarios y condiciones laborales.

Para el caso concreto de la economía de Estados Unidos, se observa que esta situación se ha dado en la realidad: tras cada crisis, las empresas 
han mejorado su carga impositiva y sus niveles de ganancias, y los trabajadores han salido de ellas con menores sueldos y mayores niveles de impuestos. El canal por el que esto ocurre siempre es político. Los gobiernos se amparan en la necesidad de tomar medidas urgentes y extraordinarias para subir el peso de los impuestos a los trabajadores, mientras que bajan los que corresponden a las empresas, ya que éstas amenazan con invertir en el extranjero dadas las "condiciones desfavorables" que se encuentran en su país.

Los beneficios empresariales después de los impuestos, medidos como porcentaje del PIB en Estados Unidos, no han dejado de crecer desde la década de 1970, y después de cada crisis ha sido el momento en el que se han consolidado los mayores aumentos. La disminución de la carga impositiva a las grandes corporaciones va asociada a la necesidad que tienen los Estados de retener el capital propio, sobre todo en épocas recesivas. Así, en estos momentos, suelen ser especialmente atendidas las demandas de rebajas fiscales por parte de los grandes capitales.

Al término de cada crisis el resultado es de claro beneficio para las grandes empresas. El canal por el que se obtienen estos beneficios proviene del mercado de trabajo, ya que el aumento del desempleo propio de la crisis alimenta el "ejército de reserva" de desempleados y deja a los trabajadores mucho más a expensas del dominio de los empresarios. Los salarios disminuyen o se congelan, y fluyen directamente hacia las arcas de los beneficios empresariales (Mitchell, 2012).

\section{Políticas neoliberales y el mercado laboral de Alemania}

Como se ha visto, las reformas de los mercados laborales se imponen en Estados Unidos a partir de finales de la década de 1970 dentro de una estrategia más amplia de los capitales internacionales para mejorar su tasa de ganancia. Estas políticas son rápidamente secundadas por la mayoría de los Estados latinoamericanos y por el gobierno conservador de Margaret Thatcher en el Reino Unido.

En ambos casos, la resistencia social a la que se enfrentaron los gobiernos que impusieron estas políticas fue feroz, y los conflictos durante las décadas de 1970 y 1980 del siglo pasado fueron recurrentes tanto en 
América Latina como en el Reino Unido y otras partes del mundo. ${ }^{7}$ Sin embargo, en los países de Europa continental estas políticas tardan en imponerse como paradigma dominante. Existen varias razones que justifican este rezago:

- El desarrollo económico de Europa después de la Segunda Guerra Mundial se basó en un crecimiento con un fuerte contenido social que permitiera estabilidad, conformando un "contrato social" entre el capital nacional, los trabajadores y sus líderes políticos.

- El "miedo" en Estados Unidos a la influencia que la extinta Unión Soviética pudiera tener sobre las amplias bases obreras de izquierdas europeas. $^{8}$

- La mayoría de los gobiernos democráticamente elegidos eran de corte socialdemócrata y existían importantes razones para pensar que el partido que implantara medidas impopulares contra los trabajadores y las bases sociales del país pagaría sus acciones con un fracaso electoral.

En el año 2000, la socialdemocracia gobernaba en la mayoría de los países de la UE-15, mientras actualmente casi han desaparecido de las labores de gobierno en la Eurozona. Mucho se ha escrito sobre las causas, pero todo parece indicar que la adopción de políticas de reformas de los mercados laborales por parte de estos gobiernos socialdemócratas fue una de las causas más importantes de este declive.

La adopción completa del recetario neoliberal: políticas de austeridad de gasto público (incluyendo gasto público social), políticas fiscales regresi-

${ }^{7}$ En el Reino Unido fue "necesaria" una guerra contra Argentina para que el gobierno de Thatcher consiguiera el apoyo suficiente para obtener una reelección en 1983 que parecía muy lejos según las encuestas de intención de voto anteriores al conflicto armado. No hay que olvidar que estas políticas son profundamente antidemocráticas y tuvieron que ser impuestas en América Latina bajo una fuerte protesta social, que en algunos casos derivó en regímenes dictatoriales apoyados por Estados Unidos, con represiones brutales, asesinatos, secuestros y desaparecidos.

${ }^{8}$ Este escenario "frenó" momentáneamente los deseos de implantar estas políticas del capital internacional en Europa continental. Además, hay que tomar en consideración que en esos años la extinta Unión Soviética ejercía como potencia antagónica a Estados Unidos y, en cierto modo, funcionó como contrapeso. 
vas (reducción de impuestos y aumento de su regresividad), desregulación de los mercados financieros (facilitando la especulación) y laborales (facilitando el despido), fueron todas ellas altamente impopulares entre sus bases electorales y causa determinante de su declive político.

En los círculos neoliberales europeos la palabra de moda es flexicurity (flexiguridad). La palabra puede sonar inglesa, pero no figura en ningún diccionario. En la Eurozona, el término es utilizado como un oxímoron, es decir, como una herramienta retórica que permite a los políticos de la uE conciliar términos contradictorios en una sola frase. Mientras que el capital debe estar contento con las referencias a la flexibilidad y la competencia en el mercado, el mundo del trabajo tiene la "tranquilidad" de que se cumplirán los compromisos a la seguridad social, el pleno empleo, el progreso social, la justicia social y la igualdad que defiende el artículo 30 de la Carta de Derechos Fundamentales de la Unión Europea.

La flexiguridad representa una ruptura con un compromiso histórico de la uE con sus trabajadores, que desde sus orígenes, la Comisión Europea defendió como base del compromiso social en el que basaba la Unión.

\section{La reforma del mercado laboral alemán: insuficiencia de demanda y patrón exportador}

Alemania es un país especial. Durante años, los historiadores han debatido sobre si el desarrollo de Alemania ha seguido una política, económica y social, Sonderweg. ${ }^{9}$ Se ha argumentado que esta vía de desarrollo especial condujo a dos guerras mundiales y a una de las dictaduras más brutales de la historia de la humanidad. Sin embargo, con la creación de la República Federal de Alemania Occidental en 1949 y la revolución democrática en la Alemania del Este tras la caída del Muro de Berlín en 1989, Alemania parece haberse convertido en una democracia occidental "normal", dele-

${ }^{9}$ Sonderweg (literalmente: "vía especial") es una teoría controvertida en la historiografía alemana que considera que las tierras de habla alemana han seguido un camino único desde la aristocracia hacia la democracia, diferente a la "vulgar" democracia occidental o la autocracia "zarística" oriental. Ver <http://dictionary.sensagent.com/ sonderweg/en-en/>. 
gando ciertos derechos de soberanía a las organizaciones internacionales y a las instituciones de la $\mathrm{UE}^{10}$ (Collignon, 2011).

Alemania es el país más grande de Europa y tiene más fronteras comunes que cualquier otra nación europea. La población de Alemania es de casi 82 millones, frente a 65 millones de franceses, 62 millones de británicos y 60 millones de italianos. Alemania es la cuarta economía más importante del mundo, después de Estados Unidos, Japón y China. Es el segundo mayor exportador mundial después de China y el segundo país con mayor superávit comercial. Asimismo, es el eje central en la política europea, tanto por su tamaño como, principalmente, por su fortaleza económica. Su PIB representa $20 \%$ de la UE, mientras Francia o el Reino Unido tienen un PIB inferior a $15 \%$. Además, es el centro europeo de fabricación, mientras las economías periféricas se han convertido en subcontratistas de ella.

A principios del siglo xxi, el gobierno alemán propone un ambicioso plan de desarrollo económico: la "Agenda 2010". Este plan surge como consecuencia de los pobres resultados que la economía alemana estaba obteniendo tanto en términos de crecimiento como de empleo desde el principio de la década de 1990. El PIB de Alemania entre 1991 y 2003 sólo había crecido 18\%, la mitad del logrado por el Reino Unido o los Países Bajos con 35\% y 34\% respectivamente. La unificación de Alemania Oriental y Occidental tuvo parte que ver en este proceso: se aumentó la fuerza laboral alemana en casi un tercio de trabajadores, muchos de los cuales no se encontraban capacitados para competir en un mercado abierto. Así, la "Política Activa del Mercado de Trabajo" alemán se encontraba "dominada por la formación y la creación de empleo público” (Bill, Mitchell y Welters, 2007).

Dentro de la "Agenda 2010", se encontraban en un lugar predominante "Las reformas Hartz". ${ }^{11}$ Este conjunto de reformas supuso el enfoque

${ }^{10}$ La política Einbindung se refiere a que Alemania desde la Segunda Guerra Mundial ha estado estrechamente ligada a sus vecinos a través de las instituciones de la Unión Europea y la Organización del Tratado del Atlántico Norte (OTAN). Este arreglo institucional se entiende que debe estar dentro del interés nacional de Alemania, ya que garantiza una paz duradera en Europa.

${ }^{11} \mathrm{Su}$ nombre proviene de una comisión de 2002, presidida por Peter Hartz, ejecutivo de Volkswagen, en la que se presenta un conjunto de recomendaciones para el mercado laboral en Alemania. 
neoliberal de la desregulación del mercado de trabajo en Alemania. Las recomendaciones de la comisión estaban en línea con las reformas de los mercados laborales que se habían aplicado en otros países industrializados tomando como base el informe de la Organización para la Cooperación y el Desarrollo Económicos (OCDE) de 1994 Jobs Study que, con el objetivo declarado de reducir el desempleo, recomendaba a los Estados centrarse en medidas de estímulo de la oferta laboral y privatizar las agencias de empleo público. El informe afirmaba que el desempleo era un problema de oferta en lugar de una falla sistémica de la economía para producir suficientes puestos de trabajo. Opinión que con el devenir de los años se ha demostrado que se trataba de una afirmación falsa.

Las recomendaciones fueron plenamente refrendadas por el gobierno socialdemócrata de Gerard Schroeder y su implantación se realizó en cuatro tramos entre 2003 y 2005. Las reformas representaron un cambio sin precedentes en las políticas de empleo que se habían mantenido estables durante varias décadas. En el marco de estas reformas, una de las medidas estrella fue la creación de los llamados "mini y midi jobs" (mini y midi empleos).

Hasta la aprobación de las reformas Hartz, los mini-jobs eran definidos como la actividad laboral de un máximo de 15 horas a la semana, y 325 euros de ingresos mensuales brutos. Los mini empleos incluían la exención completa de impuestos si el empleado no recibía ningún otro ingreso, y la exención total de las contribuciones del empleado a la seguridad social si éste era su único ingreso mensual. Las reformas del "mini trabajo" de 2003 incluyen un cambio fundamental, que con el devenir de los años se ha mostrado especialmente crítico: la restricción respecto del máximo de horas trabajadas -15 horas a la semana - fue suprimida. Como "compensación”, se aumentó el salario de estos empleos de 325 a 400 euros al mes. Así, a partir de este momento, cualquier empresario podría contratar a trabajadores con salarios "mini” pero trabajando el mismo número de horas que en su anterior puesto laboral (Bargain et al., 2005:2).

Según el propio informe, estos "empleos marginales" deberían conseguir, entre otros, los siguientes objetivos: hacer desaparecer la contratación ilegal de las personas, sobre todo en los hogares; aumentar el número de puestos de trabajo mediante la eliminación de la obligación de hacer contribuciones a la seguridad social; aumentar los incentivos para que los 
desempleados obtengan un empleo a corto plazo que sirva como "un paso intermedio" para obtener un puesto de trabajo regular.

Aparentemente, las reformas tuvieron éxito. Las estadísticas oficiales en 2004 mostraban que 930000 empleos adicionales fueron creados un mes después de la introducción de las reformas de principios de 2003 (Caliendo y Wrohlich, 2006:4). Además, "estas reformas han sido responsables de la generación de un número significativo de puestos de trabajo a tiempo parcial en el período transcurrido desde las reformas y se han relacionado con mejoras en la flexibilidad del mercado laboral" (Leschke et al., 2006:13).

Sin embargo, el aumento en el empleo no fue todo lo exitoso que los medios oficiales mostraron. Desde el fondo del ciclo, a mediados de 2003, el empleo creció mucho más lentamente que en recuperaciones anteriores. Y gran parte del aumento tuvo la forma de puestos de trabajo 'mini'; puestos de trabajo a tiempo parcial que no pagan más de 400 euros al mes, independientemente de las horas trabajadas. Por el contrario, el empleo en el mercado "primario" de trabajo, donde los gastos sociales obligatorios se encuentran todavía muy por debajo de lo que era hace siete años, el desempleo sigue siendo alrededor de cuatro millones. Y la tasa de desempleo en los Estados del Este sigue siendo el doble que en el Oeste (The Economist, 2007).

La figura de los midi-jobs se creó con el objetivo de combatir los desincentivos financieros para ganar más que el ingreso máximo que ofrece un mini-job. Según las autoridades, este contrato debía estimular a los empleadores para transformar puestos de mini-jobs en midi-jobs. No obstante, lo que realmente ocurrió es que los empleadores cambiaron puestos de trabajo "regulares" por midi o mini trabajos (Leschke et al., 2006).

La gráfica 4 informa sobre los cambios en puestos de trabajo que contribuyen marginalmente a la seguridad social (MC) (es decir, mini o midi jobs) y los puestos de trabajo que contribuyen plenamente (FC) (puestos de trabajo regulares), tras la aplicación de las reformas Hartz de principios de 2003. La creación de trabajos MC fue importante en el primer año y medio, pero se estabilizó a partir de 2005. Un patrón similar, pero a la inversa, se desarrolla para el empleo FC; el empleo FC disminuye después de la introducción de las reformas y se mantiene en los niveles a partir de 2005. En consecuencia, el efecto neto de la introducción de puestos de trabajo MC es aproximadamente la mitad del número de empleos creados FC. 
Gráfica 4. Alemania: creación de puestos de trabajo a partir de las reformas Hartz, 2003-2006

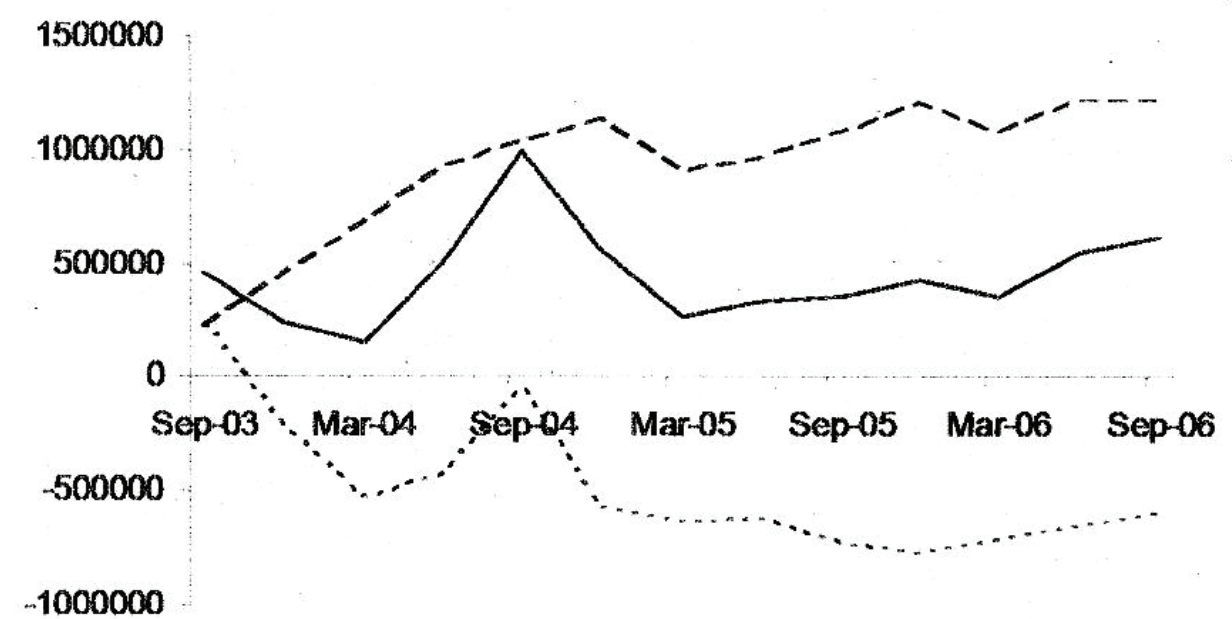

$-\ldots$ MC jobs FC jobs net total job creation

Fuente: Bill, Mitchell y Welters, 2007. Citando datos de "Statistik der Bundesagentur für Arbeit".

Las reformas Hartz consiguieron aumentar las ganancias del capital a costa de los trabajadores mediante una importante disminución de los salarios y de las condiciones laborales, y un aumento significativo de la inseguridad laboral y la precarización del mercado de trabajo. Las reformas fueron parte de una estrategia económica más amplia orientada principalmente a mantener la competitividad de las exportaciones, mientras que los empresarios alemanes se "comprometían" a no trasladar la producción al extranjero. Desde el año 2000, la media de los salarios reales se ha estancado y la desigualdad ha aumentado; en gran parte debido a la transformación de la economía alemana en una "economía de mercado" parecida a la de Estados Unidos.

El resultado, en términos de crecimiento económico, fue notable aunque cada día más dependiente de las exportaciones netas, ya que la demanda interna se está revelando incapaz de absorber la producción ale- 
mana. Alemania representa $9 \%$ de las exportaciones mundiales con $2 \%$ de la población, mientras que sus exportaciones se encuentran muy cerca de $50 \%$ en relación con el PIB. Esta estrategia si bien contribuyó a sostener la economía alemana, ha tenido un alto precio que finalizando 2012 se revela insostenible: en primer lugar, el creciente número de trabajadores alemanes con salarios demasiado bajos para permitir un nivel de vida aceptable y un consumo que estimule la demanda interna en Alemania. Asimismo, la estrategia de "devaluaciones competitivas" que Alemania impone, conduce a los países periféricos de la Eurozona a un callejón sin salida.

La entrada del euro supuso un punto de inflexión para la economía alemana y la del resto de los países de la Eurozona. De 2002 a 2010 este proceso generó un excedente de 1.62 billones de euros en Alemania, de los cuales sólo 554000 se aplicaron en su propio mercado interno para mejorar su dotación de capital o las condiciones de vida de su población. El resto, 1.07 billones, se colocó fuera de Alemania, y de esta parte, 356 000 en forma de préstamos y créditos para financiar un modelo productivo en la periferia que, lógicamente, no pudiera competir con el alemán. No obstante, Alemania tiene una importante dependencia estratégica con sus socios económicos en la Unión Europea.

La ventaja comparativa de Alemania depende en gran medida de las economías de escala obtenidas en el mercado interno de Europa, que a su vez genera ventajas para sus exportaciones en los mercados mundiales. Más de la mitad de todas las exportaciones alemanas se vende en la UE, y sin este gran mercado, la ventaja competitiva de Alemania se hundiría. Eso sin contar con la ayuda extra que Alemania recibe al disponer de una moneda subvalorada para sus exportaciones fuera de la Unión Europea.

Esta enorme ventaja no ha sido suficiente, y la estrategia de reducción de sus salarios en comparación con sus vecinos está provocando el colapso de las economías periféricas de la Eurozona en términos de desempleo y bienestar social. Tras la liberalización continua de sus mercados laborales, Alemania ha sido el país de la OCDE que más ha aumentado su desigualdad. Como resultado, la proporción de la pobreza ha aumentado de $6.5 \%$ a mediados de la década de 1990 a $11 \%$ en 2010, mientras que los ingresos reales de los salarios más bajos han caído alrededor de $10 \%$ desde el año 2000 (Stewart, 2011). 
Al igual que en Estados Unidos, los ganadores de la última década han sido las grandes empresas y las personas que se encontraban ya entre los más agraciados de la sociedad. La proporción de los salarios respecto del PIB se ha reducido, mientras que la cuota que obtienen los propietarios del capital ha aumentado de manera considerable. Los asalariados —especialmente los de baja remuneración - han sido los grandes perdedores; la proporción de trabajadores con contratos cubiertos por negociación colectiva ha caído en $15 \%$ desde el año 2000 y está ahora en torno a $60 \%$. Esta cifra demuestra la ruptura actual con el modelo social en el que se basó el crecimiento alemán hasta los años de 1990.

Debido a estas tendencias y porque Alemania no tiene un salario mínimo nacional, la economía del país depende actualmente de una creciente clase de trabajadores mal pagados. Casi $11 \%$ de los asalariados alemanes gana menos de siete euros la hora, lo que les sitúa en los niveles del salario mínimo nacional en el Reino Unido (Stewart, 2011).

Uno de los principales objetivos de la actual gobernanza económica europea es transformar los salarios en el instrumento principal de ajuste en la unión monetaria. La flexibilidad salarial propuesta incluye recortes salariales y deflaciones subregionales con el objetivo de conseguir poner a estos países en línea de competitividad con Alemania. Sin embargo, si se mira de cerca la experiencia alemana, se pone de manifiesto que este supuesto es totalmente erróneo: sus competitivos precios no son la clave del auge masivo de sus exportaciones. Lo que realmente impulsa las exportaciones alemanas es el crecimiento de sus mercados de exportación. Si las economías a las que Alemania exporta disfrutan de un auge económico, las exportaciones alemanas crecen. Un análisis de la Comisión Europea (2010) encuentra que el dinamismo de los mercados de exportación de Alemania explica $7.0 \%$ de la totalidad del $7.3 \%$ de incremento anual promedio de los volúmenes de exportación durante el periodo 1999-2008, mientras que el ajuste en los precios de las exportaciones supone un exiguo 0.3\% (Janssen, 2011).

La razón por la que una década de estancamiento de los salarios reales apenas haya tenido impacto en el auge espectacular de las exportaciones alemanas tiene que ver con el patrón de especialización de su industria, concentrándose en productos que las economías emergentes más dinámicas han estado más dispuestas a comprar (maquinaria, equipos de telecomunicaciones, infraestructuras de transporte, etcétera). 
Este tipo de patrón de especialización tiene el efecto de hacer que la demanda para el precio de las exportaciones alemanas sea muy inelástica: lo que realmente cuenta es el conocimiento técnico y la calidad. En esta situación, los precios son una cuestión subordinada. Una reducción de $10 \%$ en los precios de exportación de Alemania aumenta sus volúmenes de exportación en sólo 4\%. En el caso de Francia, una reducción similar de precios aumenta los volúmenes de exportación hasta en 12\% (Jansen, 2011).

El hecho de que la demanda de las exportaciones sea relativamente insensible a los precios también explica por qué las empresas alemanas optaron por no transmitir la caída de los costos laborales unitarios en la industria manufacturera en los precios de exportación. La alternativa de aumentar los márgenes de beneficio manteniendo los precios de exportación, mientras recortaban los salarios, era sustancialmente más atractiva.

En otras palabras, las empresas alemanas se encuentran subvencionadas por los sacrificios que se vieron obligados a realizar los trabajadores alemanes durante toda una década. Así, han aprovechado para aumentar sus márgenes de beneficio y aumentar los pagos de dividendos, en lugar de crear puestos de trabajo cada vez más competitivos. Este dato queda reflejado en la participación de las utilidades en el sector no financiero alemán, que se ha disparado de $36.3 \%$ del valor añadido bruto en 2000 a 41.4\% en 2008 (Eurostat, 2009).

\section{Conclusiones}

Desde mediados de la década de 1970 los capitales internacionales se organizaron con el objetivo de apropiarse de una mayor parte del plusvalor generado en detrimento de la parte que estaba fluyendo hacia los trabajadores. La estrategia del capital internacional se articuló en los siguientes tres ejes:

1. La flexibilización laboral.

2. La liberalización comercial y aduanera (globalización comercial).

3. La desregulación financiera (globalización financiera). 
Para desmantelar las fuerzas sindicales y alcanzar el objetivo de socavar los salarios, se precisó de la liberalización del comercio y de los mercados financieros. Así, se crea un "mercado de trabajo mundial" en el que las legislaciones protectoras hacia los trabajadores de los Estados-nación quedaron inservibles ya que los Estados, ante el temor de que sus capitalistas abandonaran el país para invertir fuera de sus fronteras, empezaron a legislar cada vez más a favor de los capitales y en contra de los trabajadores.

En el caso de Estados Unidos, principal impulsor de estas políticas, las casi cuatro décadas desde su implantación muestran importantes aumentos de la desigualdad, estancamientos salariales y disminución de los derechos sociales de los trabajadores. Esta situación ha provocado una falta de demanda efectiva solvente en la economía de este país que sólo se ha visto compensada con incrementos espectaculares del crédito financiero que se ha mostrado como una de las causas fundamentales de la actual crisis mundial que padecemos y que se encuentra muy lejos de ser resuelta.

El caso de Alemania se ha constatado que es diferente; al finalizar la Segunda Guerra Mundial el crecimiento económico se basó en un orden social que satisfacía los intereses de los capitalistas alemanes mientras se desarrollaba un "Estado del bienestar" donde los trabajadores alcanzaron amplias cotas de derechos y beneficios sociales. Esta situación tiene un punto de quiebre con la caída del Muro de Berlín, la desaparición de la Unión Soviética y la implantación a escala global de las políticas recogidas en el "Consenso de Washington", ya que durante la década de 1990 la reunificada Alemania fue perdiendo competitividad y su crecimiento era claramente inferior frente a sus principales competidores mundiales. Así, las medidas neoliberales contrarias a los derechos de los trabajadores terminan imponiéndose con las "reformas Hartz" que supusieron un giro de 180 grados respecto de las políticas de integración "empresarios-trabajadores" imperantes en Alemania desde 1945.

Los resultados han sido muy parecidos a los estudiados en el caso de Estados Unidos: aumentos muy importantes de la desigualdad, precarización laboral, constreñimiento de los salarios y pérdidas de derechos sociales. Al finalizar el año 2012, había más de seis millones de trabajadores en Alemania que mal vivían con un "mini-job" de 400 euros al mes.

Para finalizar, las reformas de los mercados laborales han conseguido excelentes resultados para los capitales internacionales a costa de los dere- 
chos de los trabajadores. No obstante, estas políticas han tenido un efecto devastador sobre los derechos sociales de los trabajadores y han supuesto aumentos sin precedentes de la desigualdad. Asimismo, la falta de una demanda solvente y efectiva que sirva de motor de la economía mundial es una las causas de las recurrentes crisis que el capitalismo padece desde finales de la década de 1970, y se encuentra en el origen de la actual crisis global que padecemos.

\section{Bibliografía}

Bargain, O., M. Caliendo, P. Haan y K. Orsini (2005), "Making Work Pay in a Rationed Labour Market: The Mini-Job Reform in Germany", documento de trabajo, núm. 536, German Institute for Economic Research, Berlín, Alemania.

Bill, A., W. Mitchell y R. Welters (2007), "Labour Reform and Labour Mobility within Cities: Have the Hartz Reforms Succeeded?", documento de trabajo, núms. 07-16, Centre of Full Employment and Equity, diciembre.

Bivens, Josh y L. Mishel (2011), Failure by Design: The Story behind America's Broken Economy, An EPI Book, Ithaca, Cornell University Press.

Caliendo, M. y K. Wrohlich (2006), "Evaluating the German 'Mini-Job' Reform Using a Natural Experiment”, documento de trabajo, German Institute for Economic Research, Berlín.

Collignon, Stefan (2011), Germany's Strategic Interest, Economic Policy Institute, 12 de mayo.

Comisión Europea (2010), "The impact of the global crisis on competitiveness and current account divergences in the euro area", Quaterly report on the Euro Area, vol. 9, núm. 1, Bussels.

Comisión Europea (2011), Annual Macro-Economic Data Base, Bruselas.

Erne, R. (2011), "Flexicurity-Useful Oxymoron or Genuine Class Compromise?", Social Europe Journal.

Eurostat (2009), "Business profit share amd investment are higher in the EU than in the USA", Statistics in fecus 28, Lexemburs.

Eurostat (2012), "News Release Euroindicators", diferentes informes.

Hacker, J. y P. Pierson (2010), Winner-Take-All Politics: How Washington Made the Rich Richer-And Turned Its Back on the Middle Class, New York Times bestsellers. Simon \& Schuster paperbacks, Nueva York.

Jacobi, L. y J. Kluve (2006), "Before and After the Hartz Reforms: The Performance of Active Labour Market Policy in Germany", documento de trabajo, núm. 2100, Institute for the Study of Labor, Bonn. 
Janssen, R. (2011), "European Economic Governance: The Next Big Hold up on Wages", Social Europe Journal, 1 de febrero.

Lee, M. y M. Mather (2008), “U.S. Labor Force Trends”, Population Bulletin, vol. 63, núm. 2, Nueva York.

Leschke, J., G. Schmid y D. Griga (2006), "On the Marriage of Flexibility and Security: Lessons from the Hartz-reforms in Germany", documento de discusión 2006-108, Wissenschaftszentrum Berlin fur Sozialforschung, Berlín.

Mishel, L., J. Bernstein y H. Shierholz (2009), The State of Working America 2008/2009, EPI, Ithaca, Cornell University Press, Nueva York.

— - J. Bivens, E. Gould y H. Shierholz (2012), The State of Working America, 12a. edición, An EPI Book, Cornell University Press, Nueva York.

Mitchell, W. (2012), "Budget Deficits are Part of 'New' Normal Private Sector Behavior", en <http://bilbo.economicoutlook.net/blog/?p=17779>, 17 de febrero.

oCDE (2011), Divided we Stand: Why Inequality Keeps Rising, oCDE, París.

- (1994), Jobs Study, OCDE, París.

Schmitt, J. (2012), "Low-wage Lessons", CEPR, Washington.

Shierholz H. (2009), "Fix it and Forget it. Index the Minimum Wage to Growth in Average Wages", Economic Policy Institute, 17 de diciembre.

Steiner V. y K. Wrohlich (2005), "Work Incentives and Labor Supply Effects of the 'Mini- Jobs Reform' in Germany”, Empirica, núm. 32, pp. 91-116.

Stewart, L. (2011), "Is the German Model all it's Cracked up to be?”, Social Europe Journal, 17 de noviembre, en <http://www.social-europe.eu/2011/11/is-thegerman-model-all-it\%E2\%80\%99s-cracked-up-to-be/>.

The Economist (2007), "Back above the bar again",12 de julio.

Artículo recibido el 12 de noviembre de 2012. Segunda versión aprobada el 26 de mayo de 2013. 